\title{
A IMPORTÂNCIA DO PLANEJAMENTO FINANCEIRO PARA O SUCESSO DAS MICROS E PEQUENAS EMPRESAS
}

Juliana de Almeida Santos, Eduardo Teraoka Tofoli, Irene Caires da Silva.

Universidade do Oeste Paulista - UNOESTE, Especialização em MBA Finanças e Controladoria, Presidente Prudente, SP. E-mail:ju almeidas@hotmail.com eduardotofoli@yahoo.com.br, irene@unoeste.br.

\section{RESUMO}

O planejamento financeiro ocupa uma posição de destaque dentro das organizações. Através dele é possível identificar os pontos fortes e fracos para a geração de recursos financeiros. Nas micro e pequenas empresas esse planejamento se faz ainda mais importante para o desenvolvimento e sobrevivência da organização, desde que muitos dos empresários não estão preparados para administrar o capital que possuem. Assim, o objetivo desse trabalho é verificar a importância do planejamento financeiro para o sucesso das micros e pequenas empresas, dando aos empresários maior aperfeiçoamento para a tomada de decisão. Para atingir esse objetivo foi realizado uma pesquisa qualitativa com profunda revisão bibliográfica, através de vários autores da área. Com a pesquisa conclui-se que, o planejamento financeiro é fundamental para todo setor empresarial, pois analisar e planejar a maneira correta em lidar com o dinheiro dentro da empresa faz com que melhore a tomada de decisão, trazendo retorno desejado, implicando no sucesso empresarial.

Palavras-chave: Planejamento Financeiro. Importância. Micro e Pequenas Empresas.

\section{THE IMPORTANCE OF FINANCIAL PLANNING FOR THE SUCCESS OF MICROS AND SMALL ENTERPRISES}

\begin{abstract}
Financial planning occupies a prominent position within organizations. Through it it is possible to identify the strengths and weaknesses for the generation of financial resources. In micro and small companies, this planning becomes even more important for the development and survival of the organization, since many entrepreneurs are not prepared to manage the capital they own. Thus, the objective of this work is to verify the importance of financial planning for the success of micro and small enterprises, giving entrepreneurs greater improvement for decision making. To achieve this goal, a qualitative research was carried out with deep bibliographical revision, through several authors of the area. The research concludes that financial planning is fundamental for every business sector, because analyzing and planning the right way to deal with money within the company makes it better decision making, bringing the desired return, implying business success.
\end{abstract}

Keywords: Financial Planning, Importance. Micro and Small Business 


\section{INTRODUÇÃO}

As micro e pequenas empresas desde sempre sofrem com a concorrência acirrada que se insere no mercado, com isso, buscam maneiras de obterem melhores resultados. $\mathrm{Na}$ busca desses resultados, veem no planejamento financeiro, uma ferramenta que pode proporcionar a empresa uma visão de futuro melhor, auxiliando em uma melhor tomada de decisão.

O planejamento é apontado como a ferramenta de maior importância para alcançar objetivos e se faz necessário em todas as áreas, assim as micro e pequenas empresas entendendo que não se deve viver de imprevistos e considerando a forma como são gerenciadas precisam cada vez mais de ferramentas que possibilitam agilidade e segurança no processo decisório, com isso o planejamento financeiro é indispensável para que haja sucesso, pois só com organização não é possível controlar as ações do dia a dia, conquistar seus objetivos e sobreviver no mercado.

A falta de planejamento em relação as questões financeiras é uma das principais razões para o fracasso de empresas no Brasil. Entender que não se tem controle total da situação e que imprevistos podem surgir é um dos primeiros passos para evitar surpresas desagradáveis e se preparar para superá-las.

O processo de planejamento auxilia na necessidade de sobrevivência das micros e pequenas empresas, identificando os problemas e desafios futuros, sendo possível estabelecer a melhor direção a ser seguida, também estipula metas, a fim de tornar cada dia mais eficiente à atuação da empresa no mercado.

Sabendo disso, esse estudo tem como objetivo verificar a importância do planejamento financeiro para o sucesso das micros e pequenas empresas, dando aos empresários dessas organizações maior aperfeiçoamento para a tomada de decisão. Para atingir esse objetivo foi realizado uma pesquisa qualitativa com uma profunda revisão bibliográfica através de vários autores sobre o assunto, com base em livros técnicos da área de Administração Financeira, e em artigos científicos via Internet na área de Planejamento Financeiro.

\section{METODOLOGIA}

A metodologia utilizada para a realização desse trabalho, foi uma pesquisa qualitativa onde "busca-se descrever a complexidade de uma hipótese ou problema, analisar a interpretação de certas variáveis, compreender e classificar processos dinâmicos experimentados por grupos sociais" (YIN, 2005, p. 117).

Para que tal pesquisa fosse bem elaborada foi necessária a consulta de uma revisão bibliográfica através de vários autores sobre o assunto, com base em livros técnicos da área de Administração Financeira, como em artigos científicos via Internet na área de Planejamento Financeiro.

De acordo com Marconi e Lakatos (1996, p. 66), a pesquisa bibliográfica "oferece meios para definir, resolver não somente problemas já conhecidos, como também explorar novas áreas onde os problemas não se cristalizaram suficientemente".

A presente pesquisa se caracteriza como exploratório, na medida que por meio desse estudo, busca-se conhecer com maior profundidade o assunto de modo a torná-lo mais claro ou construir questões importantes para a condução da pesquisa. 


\section{REFERENCIAL TEÓRICO}

\section{PLANEJAMENTO FINANCEIRO}

O planejamento financeiro traça estratégias para alcançar resultados levando em consideração a capacidade da empresa e apresentam os valores que podem afetar os resultados esperados, possibilitando ao gestor ter ferramentas, relatórios e informações para a tomada de decisão (LACOMBE, 2009).

Segundo Lacombe (2009, p. 70) “o planejamento é um poderoso instrumento de intervenção na realidade e que, se bem utilizado, constitui ferramenta fundamental para o desenvolvimento das organizações." Para Vasconcellos Filho $(1979$, p. 882) "o planejamento é uma técnica para estabelecer e manter o sentido de direção, a fim de que as pessoas possam atuar de maneira consistente para fazer o progresso naquela direção.

O planejamento financeiro sendo bem utilizado é uma ferramenta essencial que determina com antecipação as ações que serão necessárias, as decisões a serem tomadas e o modo de como deve agir para alcançar seus objetivos. Quando há planejamento é possível informar as oportunidades e dificuldades para cumprir as obrigações com antecedência, dentro da empresa, evitando imprevistos e traçando planos para desenvolver alternativas e superá-las.

As empresas vivem em um ambiente extremamente competitivo, se não planejarem suas atividades corre o risco de serem surpreendidas por imprevistos e passarem por grandes dificuldades ou até mesmo chegar à falência. $O$ planejamento financeiro deve ser usado como ferramenta para decidir antecipadamente o que fazer, de que maneira fazer, quando fazer e quem deve fazer (LOURDES JUNIOR, 2010).

Chiavenato (2004, p.166) escreveu que:

O planejamento é a função administrativa que determina antecipadamente quais são os objetivos a serem atingidos e como se deve fazer para alcançá-los. Trata-se, pois, de um modelo teórico para a ação futura. Começa com a determinação dos objetivos e detalha os planos necessários para atingi-los da melhor maneira possível. Planejar é definir os objetivos e escolher antecipadamente o melhor curso de ação para alcançá-los. O planejamento define onde se pretende chegar, o que deve ser feito, quando, como e em que sequência.

Maximiano (1995, p. 197) define o processo de planejamento das seguintes formas:

É o processo de definir objetivos ou resultados a ser alcançados, bem como os meios para atingi-los; É o processo de interferir na realidade, com o propósito de passar de uma situação conhecida para outra situação desejada, dentro de um intervalo definido de tempo; É tomar no presente decisões que afetam o futuro, visando a reduzir sua incerteza

Desta Forma, planejamento financeiro é estabelecer e seguir uma estratégia, visando atingir objetivos. Através de um conjunto de ações e procedimentos, o planejamento possibilita, entre outras coisas, montar um orçamento, acompanhar as contas, saber se há sobra ou falta de recursos, tomar providências para nivelar o orçamento (LACOMBE, 2009).

Através dos relatórios financeiros e contábeis, o fluxo de caixa e os orçamentos feitos a empresa tem uma visão dos acontecimentos que irão enfrentar em certos períodos, e com planejamento tem a possibilidade de orientar de forma mais preparadas e não arriscar o capital que não possui (LACOMBE, 2009).

Com isso, planejar o setor financeiro é elaborar táticas, para que a empresa possa chegar aos objetivos, que venha a ser de curto, médio ou longo prazo, da forma mais 
estruturada e precisa possível. Alcançando esta arte, a empresa obtém o seu desenvolvimento financeiro e estrutural planejado com mais eficácia e se prepara para a competitividade (LACOMBE, 2009).

Uma das ferramentas do planejamento financeiro é o fluxo de caixa, que permite ao gestor ter uma visão melhor do seu caixa.

Conforme Zdanowicz (1992 p. 38) "o fluxo de caixa é o instrumento que permite ao administrador financeiro: planejar, organizar, coordenar, dirigir e controlar os recursos financeiros de sua empresa para um determinado período".

O fluxo de caixa é o registro de entrada e saída de dinheiro da empresa, através desse controle o empresário tem uma visão do presente e do futuro, sendo bem controlado evita problemas de liquidez e é uma indispensável ferramenta no processo de planejamento.

\section{MICROS E PEQUENAS EMPRESAS}

Atualmente no Brasil existem 6,4 milhões de estabelecimentos, desse total 99\% são micro e pequenas empresas segundo dados do SEBRAE (2013).

Esse valor se justifica pelo fato dessas empresas apresentarem um baixo nível de complexidade em suas operações, fato esse que pode ser bem aproveitado, pois na maioria das vezes os sócios desempenham desde as tarefas operacionais até as tarefas gerenciais, possibilitando assim que tenham maior conhecimento de suas atividades, contribuindo para que a administração e suas funções de planejamento, organização, direção e controle, sejam desempenhadas de formas mais práticas, já que a decisão e controle de todos os setores passam por suas mãos.

Muitas vezes o desenvolvimento das MPEs não demonstra tanta eficiência por apresentarem uma má administração, pois muitos empresários ainda não possuem o conhecimento da necessidade e importância do planejamento financeiro, o que dificulta muito a sobrevivência da empresa no mercado (ROSA; LIMA, 2008).

Com base nisto, é necessário que os gestores das micros e pequenas empresas tenham informações e aprendam a arte de organização para planejar e controlar suas ações, para que permaneça no mercado e possua recursos para fazer circular bens, serviços, gerar riquezas e não correr o risco de deixar de existir.

\section{PLANEJAMENTO FINANCEIRO NAS MICRO E PEQUENAS EMPRESAS}

As micros e pequenas empresas sobrem uma pressão muito grande no mercado, com isso, o planejamento acaba representando um dos fatores primordiais no processo da administração, através dele é possível verifica a realidade da empresa, definir os rumos, criar uma perspectiva futura, organizar-se e definir as ações futuras. Desta forma, o planejamento e o planejamento financeiro, são fator de racionalização da atividade das micros e pequenas empresas.

$\mathrm{Na}$ ausência de um planejamento financeiro, torna-se praticamente inviável a realização as projeções, análises e aplicação de investimentos na forma e tempo corretos, levantamento de custos e verificação de oportunidades de direcionamento econômico (LACOMBE, 2009).

O planejamento financeiro é uma parte importante do trabalho do administrador financeiro. Os planos financeiros e orçamentos fornecem roteiros para atingir os objetivos da empresa. Além disso, esses veículos oferecem uma estrutura para coordenar as diversas atividades da empresa e atuam como mecanismo de controle, estabelecendo um padrão de desempenho contra o qual é possível avaliar os eventos reais (TOFOLI, 2008). 
Obviamente, é preciso entender as principais dimensões do processo de planejamento financeiro para administrar eficientemente as atividades financeiras da empresa e, consequentemente, maximizar o preço de sua ação (GITMAN, 1997).

Nas micros e pequenas empresas, o planejamento financeiro direciona a mesma e estabelece o modo pelo qual os objetivos financeiros podem ser alcançados. Um plano financeiro é, portanto, uma declaração do que deve ser feito no futuro. Em sua maioria, as decisões numa empresa demoram bastante para serem implantadas. Numa situação de incerteza, isso exige que as decisões sejam analisadas com grande antecedência (LACOMBE, 2009).

Desta forma, o planejamento financeiro nas micros e pequenas empresas mostramse essencial no processo de sua gestão, no sentido em que fornece um orçamento gerencial, que propicia a consolidação dos objetivos, servindo como um acervo informativo para diversos setores da empresa que carecem de orientação e controle.

\section{A IMPORTÂNCIA DO PLANEJAMENTO FINANCEIRO NAS MICROS E PEQUENAS EMPRESAS}

A capacidade de planejamento é uma das habilidades mais importantes de uma empresa bem-sucedida, isso porque defini os objetos e metas além de dar sentido e direção ao caminho que a empresa irá percorrer (SILVA; PERUZZI, 2015).

De acordo com Silva e Peruzzi (2015, p. 06) "planejar é traçar metas, organizar planos em direção às características de um projeto que se deseja pôr em prática, e finanças quer dizer dinheiro, fortuna, informação da modificação da moeda".

O planejamento financeiro é mais do que importante, é indispensável. Porque, no fundo, é a base para quase todas as práticas na empresa. Nota-se a importância de compreender que o planejamento financeiro faz toda diferença dentro de qualquer organização, sendo um dos pontos essencial para o bom andamento e progresso das atividades, visando que sem planejamento a empresa fica sem foco (MARION, 2005).

Os gestores de micro e pequenas empresas que buscam formas de acrescentar a administração ferramentas que auxiliem para melhores resultados no processo decisório, percebem que o planejamento financeiro traz umas das principais vantagens pois dá a possibilidade de prever as ameaças e oportunidades, define onde se pretende chegar, o que deve ser feito, quando, como e em que sequência. Muitos gestores ainda ignoram essa ferramenta, em consequência disso as taxas das micro e pequenas empresas que deixam de existir ainda nos primeiros anos de funcionamento são elevadas (ROSA; LIMA, 2008).

Para Gitman (1997, p.588) “o planejamento financeiro é um dos aspectos importantes para funcionamento e sustentação de uma empresa, pois fornece roteiros para dirigir, coordenar e controlar suas ações na consecução de seus objetivos".

Maximiano (1995, p. 197) diz que "a necessidade maior de planejar está relacionada a três situações: enfrentar fatos que certamente ocorrerão, criar um futuro desejável e coordenar fatos entre si".

A importância de se fazer um planejamento financeiro está associada ao sucesso que a empresa pretende alcançar, pois através dele, consegue-se traçar metas a longo e curto prazo tornando possível que os objetivos sejam atingidos. O planejamento financeiro é a fonte para que a organização tenha continuidade, pois sem ele é difícil tomar decisões corretas (GRODISKI, 2008).

O planejamento financeiro apresenta vantagens reais para as pequenas empresas e para as grandes, pois ajuda a assegurar o seu desenvolvimento, acelera o ritmo de mudança, 
conduz a ação eficiente e força o dirigente a ter algum controle sobre o seu futuro (TOFOLI, 2008).

Assim, nos tempos de crises as MPEs começam a entender que precisam dar a devida importância para o planejamento, sabendo que se planejar torna a empresa melhor gerenciada aumentando as chances de alcançar os objetivos desejados e sua competitividade no mercado, deixando de lado o medo e a insegurança de sobrevivência.

\section{RESULTADOS}

Tanto para a vida pessoal como para as empresas é muito importante e necessário o planejamento financeiro. No mundo dos negócios as micros e pequenas empresas necessitam ter consciência da importância de se planejar, pois é esse planejamento que dará suporte para as ações e resultados futuros.

O planejamento financeiro representa um dos fatores principais no processo administrativo das micro e pequenas empresas, pois elas sofrerem pressão no grande mercado devido a sua concorrência cada vez maior. Através dele é possível constatar a realidade em que a empresa está inserida, o que possibilita definir seus rumos, criar uma perspectiva de trabalho, organizar-se e então definir as ações futuras a serem tomadas.

Assim é essencial que os gestores dessas empresas tenham informações precisas e se adequem a uma visão sistêmica, para planejar e controlar sua tomada de decisão, e obter bons resultados para que permaneça no mercado, possuindo recursos para circulação de bens, serviço, gerar riquezas e não correr o risco de ser extinta do seu meio.

\section{DISCUSSÃO}

O tempo dedicado ao planejamento é essencial para evitar problemas na fase de execução de suas atividades. O planejamento tem o propósito de passar de uma situação conhecida para uma situação desejada, tem o objetivo de minimizar a necessidade de revisões, e tomar decisão com mais segurança, mas somente planejar não assegura a realização dos planos, também é necessário que exista controle, acompanhar as ações do dia a dia e comparar o desempenho real com o planejado.

São muitas as questões que rodeiam o dia a dia dos gestores, das micros e pequenas empresas, no entanto, a palavra que é fundamental para conseguir diminuir as despesas, controlar os custos e tomar decisões mais acertadas é o planejamento. Seguindo esse planejamento com a devida importância que merece os gestores ganham uma ferramenta essencial no desenvolvimento e sucesso da organização (LACOMBE, 2009).

Observando as pequenas empresas é possível perceber a dificuldade dos gestores a se adequarem no processo de seguir o que foi planejado, muitas vezes sabem que precisam seguir o caminho para alcançar os objetivos traçados, mas ainda resistem quando surgem as surpresas do dia a dia. Assim, percebe-se que falta tomada de consciência da importância de planejar e controlar o que foi planejado de forma competente para o desenvolvimento e sucesso da empresa (TOFOLI, 2008).

Não possuindo um bom planejamento financeiro diminuem muito as chances das micro e pequenas empresas conseguirem sucesso ou ser competitiva, desde que não conhecendo bem suas finanças não saberá como utilizá-las de forma estratégica. Quando há um bom planejamento financeiro os gestores ficam motivados a alcançar cada vez mais os resultados traçados, contribuindo assim para o crescimento da organização. 


\section{CONCLUSÃO}

O planejamento financeiro é uma ferramenta fundamental para o desenvolvimento e crescimento de uma organização, pois por meio dele que o gestor tem real conhecimento da situação financeira da empresa. Para tomar as decisões corretas é necessário ter um planejamento financeiro bem elaborado, a fim de estar melhor preparado para as surpresas.

É através do planejamento financeiro que a empresa tem o direcionamento para poder atingir os seus objetivos.

Com a pesquisa, foi possível verificar a importância do planejamento financeiro nas micro e pequenas empresas, sabendo que muitas vezes o empresário não entende como administrar os recursos adquiridos, e passam a ter uma visão da necessidade de planejar e controlar suas ações para a sobrevivência das empresas, atingindo assim, o objetivo desse trabalho.

Para administrar com eficiência e eficácia as micro e pequenos empresas, é fundamental, dentre outros fatores, o domínio do planejamento, controle e conhecimento de todas as informações dos resultados, pois com o mercado competitivo de hoje, produzir e vender bem não é mais suficiente, há necessidade de controlar com segurança as finanças das atividades.

Por isso, é de suma importância planejar e controlar financeiramente todos os passos das MPEs corretamente, para que as decisões sejam tomadas da melhor forma possível, sabendo-se que no mundo dos negócios nunca pode ter certeza do futuro e viver de imprevistos, pois a concorrência sempre pode trazer surpresas aos gestores.

Portanto, pode se concluir que o planejamento financeiro, associado com controle é fundamental para todas as MPEs alcançarem sucesso, analisando e planejando de que maneira lidam com o dinheiro dentro do orçamento buscando o retorno desejado.

Assim esse estudo nos levou a compreender que um planejamento financeiro bem feito é indispensável para as micro e pequenas empresas, pois possibilita saber com antecedência, que caminhos estão sendo trilhados, visando os resultados financeiros, trazendo tranquilidade e considerando que no mundo empresarial não há espaço para improvisos.

\section{REFERÊNCIAS}

CHIAVENATO, I. Introdução à Teoria Geral da Administração. 7 ed. rev. e atual. Rio de Janeiro: Elsevier, 2004.

GITMAN, L. J. Princípios da administração financeira. São Paulo: Habra, 1997.

GRODISKI, H. R. A importância do planejamento financeiro e controle financeiro para o desempenho empresarial. 2008. Disponível em: <http://www.artigonal.com/gestãoartigos/a-importancia-do-planejamnto-e-controle-financeiro-para-o-desempenhoempresarial-386410.html>. Acesso em: 14 maio 2018.

LACOMBE, F. Teoria geral da administração. São Paulo: Saraiva, 2009.

LOURDES JÚNIOR, J. de A.R. Administração financeira e orçamentária. Centro Estadual de Educação Profissionalizante Francisco Carneiro Martins, 2010. Disponível em: https://professorfernando.wikispaces.com/file/view/Apostila+de+Administra\%C3\%A7\%C3\% A3o+Financeira+e+Or\%C3\%A7ament\%C3\%A1ria.pdf. Acesso em: 03 jul. 2018. 
MARCONI, M.de A, LAKATOS, E. M. Técnicas de pesquisa. 3 ed. São Paulo: Atlas, 1996.

MAXIMIANO, A. C. A. Introdução à administração. 4 ed. São Paulo: Atlas, 1995.

ROSA, Janaina Alves, LIMA Robernei Aparecido. A IMPORTÂNCIA DO PLANEJAMENTO FINANCEIRO PARA MICRO E PEQUENAS EMPRESAS, Disponível em:http://www.inicepg.univap.br/cd/INIC 2008/anais/arquivosINIC/INIC1213 $010 . p d f$, Acesso em: 27/07/2018.

SILVA, A. da C; PERUZZI, M. H. de A. Controladoria e Planejamento financeiro. Docente Esp. do Curso de Tecnologia em Gestão Financeira das Faculdades Integradas de Três Lagoas AEMS Disponível em: https://docplayer.com.br/887552-Controladoria-e-planejamentofinanceiro.html. Acesso em: 04/07/2018.

SEBRAE. Serviço de Apoio à Micro e Pequena Empresa. Controles Administrativos. Disponível em: http://www.sebrae.com.br/sites/PortalSebrae/ufs/sp/sebraeaz/pequenos-negociosem-numeros,12e8794363447510VgnVCM1000004c00210aRCRD. Acesso em: 29/07/2018

TÓFOLI, I. Administração financeira empresarial: uma tratativa prática. Campinas: Arte Brasil, 2008.

VASCONCELLOS FILHO, Paulo de. Planejamento estratégico: formulação, implantação e controle. Rio de Janeiro: Livros Técnicos e Científicos, 1982.

YIN, R. K. Estudo de caso: planejamento e método. Porto Alegre: Bookman, 2005.

ZDANOWICZ, José Eduardo. Fluxo de caixa: uma decisão de planejamento e controle financeiros. Porto Alegre: Sagra, 1992. 